\title{
Low tidal volume mechanical ventilation against no ventilation during cardiopulmonary bypass heart surgery (MECANO): study protocol for a randomized controlled trial
}

Lee S. Nguyen ${ }^{1 *}$, Messaouda Merzoug ${ }^{1}$, Philippe Estagnasie ${ }^{1}$, Alain Brusset ${ }^{1}$, Jean-Dominique Law Koune ${ }^{3}$, Stephane Aubert ${ }^{2}$, Thierry Waldmann², Jean-Michel Grinda ${ }^{2}$, Hadrien Gibert ${ }^{3}$ and Pierre Squara ${ }^{1}$

\begin{abstract}
Background: Postoperative pulmonary complications are a leading cause of morbidity and mortality after cardiac surgery. There are no recommendations on mechanical ventilation associated with cardiopulmonary bypass (CPB) during surgery and anesthesiologists perform either no ventilation (noV) at all during CPB or maintain low tidal volume (LTV) ventilation. Indirect evidence points towards better pulmonary outcomes when LTV is performed but no large-scale prospective trial has yet been published in cardiac surgery.

Design: The MECANO trial is a single-center, double-blind, randomized, controlled trial comparing two mechanical ventilation strategies, noV and LTV, during cardiac surgery with CPB. In total, 1500 patients are expected to be included, without any restrictions. They will be randomized between noV and LTV on a 1:1 ratio. The noV group will receive no ventilation during CPB. The LTV group will receive 5 breaths/minute with a tidal volume of $3 \mathrm{~mL} / \mathrm{kg}$ and positive end-expiratory pressure of $5 \mathrm{cmH} 2 \mathrm{O}$. The primary endpoint will be a composite of all-cause mortality, early respiratory failure defined as a ratio of partial pressure of oxygen/fraction of inspired oxygen $<200 \mathrm{mmHg}$ at 1 hour after arrival in the ICU, heavy oxygenation support (defined as a patient requiring either non-invasive ventilation, mechanical ventilation or high-flow oxygen) at 2 days after arrival in the ICU or ventilator-acquired pneumonia defined by the Center of Disease Control. Lung recruitment maneuvers will be performed in the noV and LTV groups at the end of surgery and at arrival in ICU with an insufflation at $+30 \mathrm{cmH} 20$ for 5 seconds. Secondary endpoints are those composing the primary endpoint with the addition of pneumothorax, CPB duration, quantity of postoperative bleeding, red blood cell transfusions, revision surgery requirements, length of stay in the ICU and in the hospital and total hospitalization costs. Patients will be followed until hospital discharge.
\end{abstract}

Discussion: The MECANO trial is the first of its kind to compare in a double-blind design, a no-ventilation to a lowtidal volume strategy for mechanical ventilation during cardiac surgery with CPB, with a primary composite outcome including death, respiratory failure and postoperative pneumonia.

Trial registration: ClinicalTrials.gov, NCT03098524. Registered on 27 February 2017.

Keywords: Cardiopulmonary bypass, Postoperative pulmonary complications, Protective ventilation, Low tidal volume

\footnotetext{
* Correspondence: nguyen.lee@icloud.com

${ }^{1}$ Critical Care Medicine Department, CMC Ambroise Paré, 25-27 Boulevard

Victor Hugo, 92200 Neuilly-sur-Seine, France

Full list of author information is available at the end of the article
} 


\section{Background}

Ventilator-acquired pneumonia (VAP) is a common postoperative complication and accounts for a large part of post-cardiac surgery morbidity and mortality. Incidence of VAP depends on numerous factors, including pulmonary collapse and atelectasis during cardiopulmonary bypass $(\mathrm{CPB})$, lowering of bronchial arterial blood flow and systemic inflammation response syndrome during and after CPB [1-6].

To date, the impact of mechanical ventilation during $\mathrm{CPB}$ is unknown. On the one hand, $\mathrm{CPB}$ allows blood oxygenation during cardiac surgery, regardless of heartbeat and oscillations, allowing the surgeon to operate without disturbance [7]. On the other hand, postoperative pulmonary complications appear to be more frequent when no mechanical ventilation is maintained while under $\mathrm{CPB}$ [8].

A recent meta-analysis identified oxygenation improvement after the weaning from $\mathrm{CPB}$ when low tidal volume (LTV) ventilation was maintained or after lung recruitment maneuvers (LRM), as compared to when there was no ventilation (noV) [9]. Furthermore, maintaining mechanical ventilation may reduce the inflammation response and tissue damage $[10,11]$. As the design of previous studies did not include hard clinical endpoints such as respiratory complications, death or length of stay, there is as yet no evidence for an unquestionable standardized strategy of lung protection during $\mathrm{CPB}$ and there are no scientific recommendations on whether mechanical ventilation has to be maintained during cardiac surgery or not, notably between LTV ventilation and noV [12]. Last, the nature of the intervention makes it hard for protocol investigators to blind the investigators to the intervention, explaining why all trials assessing mechanical ventilation are open-labeled [13].

The trial - low tidal mechanical ventilation against no ventilation during cardiopulmonary bypass heart surgery ("MECANO") - aims to prove the superiority of the LTV compared to the noV strategy during CPB in cardiac surgery, to decrease postoperative respiratory complications, assessed by hard clinical endpoints using a double-blind design.

\section{Methods/design \\ Methods}

The MECANO trial is a single-center, double-blind, non-pharmacological, randomized, controlled trial comparing two mechanical ventilation strategies, LTV and noV, during cardiac surgery with CPB (Fig. 1).

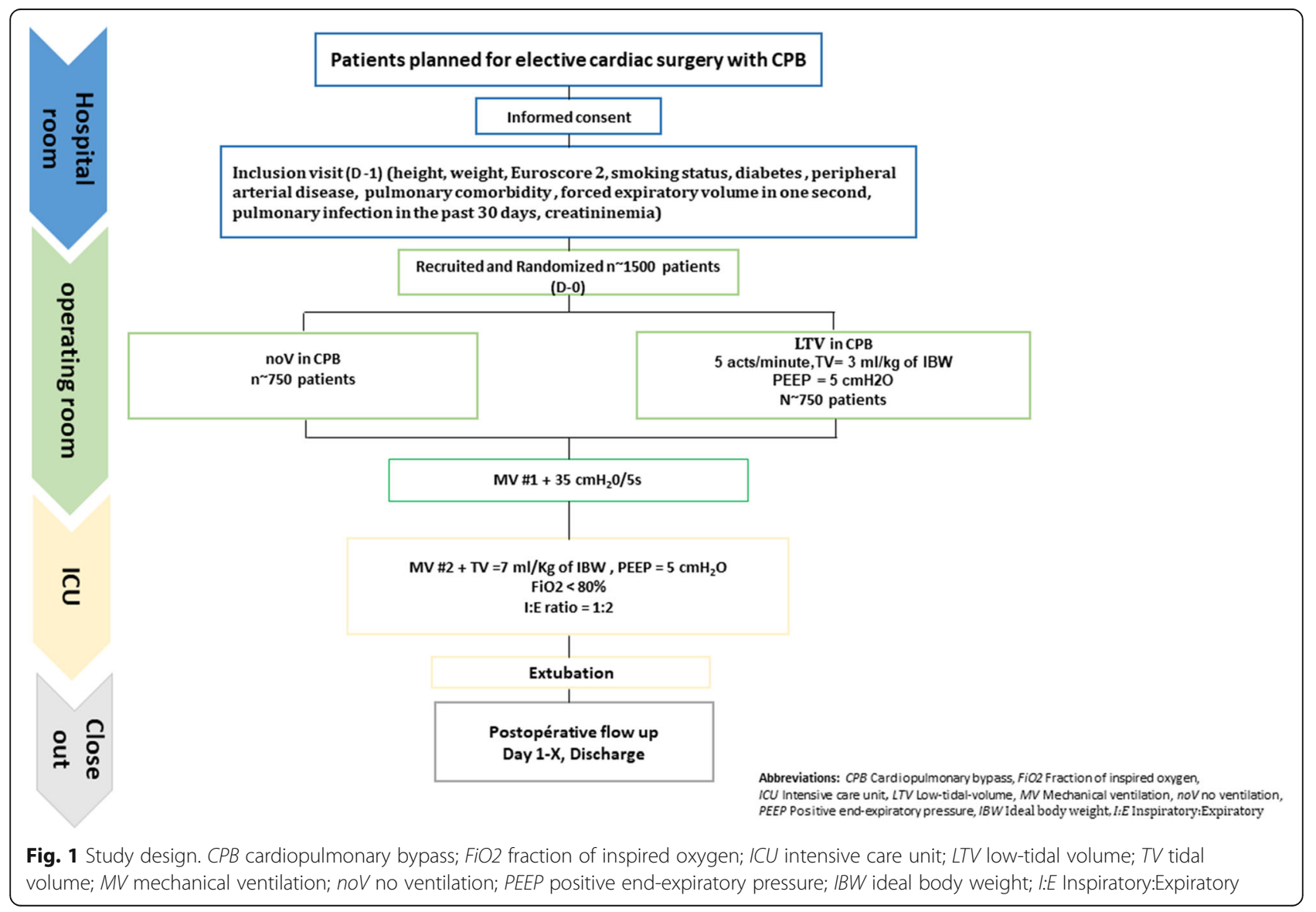




\section{Population}

All patients aged more than 18 years and planned for elective cardiac surgery with CPB are eligible. Thoracoscopic surgery procedures are excluded. The inclusion and exclusion criteria are shown in Table 1.

\section{Endpoints}

The primary endpoint is a composite of overall death, early respiratory failure defined as partial pressure of oxygen $(\mathrm{PaO} 2) /$ fraction of inspired oxygen $(\mathrm{FiO} 2)$ ratio $<200$ at 1 hour after arrival in the intensive care unit (ICU), heavy oxygenation support (defined as a patient requiring either non-invasive ventilation, mechanical ventilation, or highflow oxygen) at 2 days after arrival in the ICU or VAP as defined by the Center of Disease Control [14]. Secondary endpoints are those composing the primary endpoint with the addition of pneumothorax, $\mathrm{CPB}$ duration, volume of postoperative bleeding, red blood cell transfusions, requirements for revision surgery, length of stay in the ICU and in the hospital and total hospitalization costs. Patients are followed until hospital discharge (Table 2).

\section{Randomization}

Randomization is performed by the anesthesiologist in charge upon the patient's arrival in the operating room using an external interactive web response system (IWRS). A 1:1 treatment ratio with blocks of various even size (to prohibit prior guessing of the allocation group) is used. Thus, physicians outside the operating room (i.e. study investigators) are not aware of the treatment arm. Any deviation from the protocol is recorded, as is the reason for deviation.

\section{Intervention}

The noV group receives no ventilation during $\mathrm{CPB}$. The LTV group receives 5 breaths/minute with a tidal volume of $3 \mathrm{~mL} / \mathrm{kg}$ and positive end-expiratory pressure (PEEP) of $5 \mathrm{cmH} 2 \mathrm{O}$. Lung recruitment maneuvers are performed in both groups at the end of surgery when thorax is closed and on arrival in the ICU, with insufflation at $+30 \mathrm{cmH} 20$ for 5 seconds. In the ICU, the ventilation strategy is lung-protective: tidal volume $=6 \mathrm{~mL} / \mathrm{kg}$ of ideal body weight, PEEP $=5 \mathrm{cmH} 2 \mathrm{O}, \mathrm{FiO} 2$ set to obtain $\mathrm{PaO} 2$ between 200 and $250 \mathrm{mmHg}$, inspiration/expiration time ratio $=1: 2$. Other therapeutic approaches are left to the decision of the ICU intensivists.

\section{Data collection}

All data are recorded on a dedicated online case report form (CRF). Preoperative data are collected prior to surgery (age, height, weight, EuroSCORE 2, smoking status, diabetes mellitus, peripheral arterial disease, pulmonary comorbidity, forced expiratory volume in one second, pulmonary infection in the past 30 days and creatininemia).
Table 1 Eligibility criteria

\begin{tabular}{ll}
\hline Inclusion criteria & Exclusion \\
\hline Signed informed consent & Unplanned surgery (emergency) \\
Age $>18$ years & Pregnant women \\
Planned surgery with CPB & $\begin{array}{l}\text { Inability to understand the informed } \\
\text { consent }\end{array}$ \\
Affiliation to French Social & $\begin{array}{l}\text { Impossibility to wean CPB at the end of } \\
\text { Security }\end{array}$ \\
& Thoracoscopic surgery \\
\hline
\end{tabular}

$C P B$ cardiopulmonary bypass

Variables linked to the surgery are type of procedure, duration of CPB (in minutes), number of red blood cell transfusions and numbers of and reasons for manual insufflation. Data collected on daily visits are systematically recorded for 3 days, including temperature, $\mathrm{PaO} 2, \mathrm{FiO} 2$, ventilation mode, hemoglobinemia, leucocytemia and quantity of bleeding. Endpoints described earlier and time to event are tracked throughout hospitalization with follow up maintained until hospital discharge (Table 3).

\section{Statistical considerations}

Sample-size calculation is based on two-sided alpha error of 0.05 and $80 \%$ power. Based on respiratory insufficiency incidence after cardiac surgery, we anticipate that at least $25 \%$ of patients will present with postoperative respiratory complications. We expect a relative

Table 2 Endpoints

\begin{tabular}{ll}
\hline Endpoint \\
\hline Primary & All-cause mortality \\
& Early respiratory failure (PaO2/FiO2 ratio $<200$ in the first hour after \\
& transfer to ICU after surgery) \\
& Late respiratory failure (heavy oxygenation support \\
(non-invasive ventilation, high-flow oxygen or mechanical ventilation) & 2 days after surgery) \\
& Ventilator-acquired pneumonia \\
& Early pneumonia (early or ventilator-acquired) \\
Secondary & All-cause in-hospital mortality \\
& Early respiratory failure \\
& Heavy oxygenation support \\
& Pneumonia \\
& Length of stay in the ICU (days) after the initial \\
cardiac surgery) & Length of stay in the hospital (days) after the initial cardiac surgery \\
& Cost of hospitalization (euros) \\
& Revision surgery (requirement for any revision cardiac surgery after \\
the initial surgery) & Pneumothorax (diagnosed on chest x-ray or $C T$-scan occurring after \\
the initial surgery) \\
Postoperative bleeding (mL) \\
Cardiopulmonary bypass duration (minutes) \\
Red blood cells transfusion (units) \\
Other
\end{tabular}

$\mathrm{PaO2} / \mathrm{FiO} 2$ partial pressure of oxygen/fraction of inspired oxygen; $C T$ scan computerized tomography scanner 
improvement in the incidence of the primary outcome of $20 \%$ between the two arms (odds ratio 0.8 in favor of the LTV arm as compared to the noV arm). The required sample size is then 720 patients per group, 1440 patients in total. Accounting for the attrition ratio, 1500 patients will be included. Interim analyses will be performed. The sample size will be recalculated after every analysis based on the conditional probability of the final outcome.

\section{Data analysis}

Patients will be analyzed following the intention-to-treat principle. Binomial regression eventually supplemented by modified logistic regression (Diaz-Quijano, BMC
Medical Research Methodology 2012, 12:14) and survival regression will be performed for statistical analysis. Relative risks and hazard ratio with 95\% confidence intervals and differences between medians with 95\% confidence intervals will be calculated by bootstrapping (3000 iterations) when appropriate. Two-sided significance tests will be used throughout. We will infer a subgroup effect if the interaction term of treatment and subgroup is statistically significant at $P<0.05$.

\section{Ethical approval and clinical trial authorization}

The trial is conducted in adherence to the current version of the Helsinki Declaration, the French Law on Protection

Table 3 Flow-chart: enrollment, interventions and evaluations

\begin{tabular}{|c|c|c|c|c|c|c|c|c|}
\hline \multirow{3}{*}{ Time points ${ }^{\mathrm{a}}$} & \multirow{3}{*}{$\begin{array}{l}\text { Enrollment } \\
\text { Preoprative visit } \\
\text { (D-1 or D-2 before surgery) }\end{array}$} & \multicolumn{7}{|c|}{ Study period } \\
\hline & & \multicolumn{2}{|l|}{$\begin{array}{l}\text { Allocation/ } \\
\text { intervention }\end{array}$} & \multicolumn{3}{|c|}{ Post intervention } & \multirow{2}{*}{$\begin{array}{l}\text { Follow } \\
\text { up } \\
\text { Day X }\end{array}$} & \multirow{2}{*}{$\begin{array}{l}\text { Close out } \\
\text { Hospital } \\
\text { discharge }\end{array}$} \\
\hline & & $\begin{array}{l}\text { Before } \\
\text { anesthesia }\end{array}$ & $\begin{array}{l}\text { During } \\
\text { surgery }\end{array}$ & $\begin{array}{l}\text { Day } \\
1\end{array}$ & $\begin{array}{l}\text { Day } \\
2\end{array}$ & $\begin{array}{l}\text { Day } \\
3\end{array}$ & & \\
\hline \multicolumn{9}{|l|}{ Enrollment } \\
\hline Eligibility screen & $x$ & & & & & & & \\
\hline Informed consent & $x$ & & & & & & & \\
\hline Physical examination ${ }^{b}$ & $x$ & & & & & & & \\
\hline History of previous disease ${ }^{c}$ & $x$ & & & & & & & \\
\hline FEV (1) and FVC & $x$ & & & & & & & \\
\hline Euroscore 2 & $x$ & & & & & & & \\
\hline Creatininemia $(\mu \mathrm{mol} / \mathrm{L})$ & X & & & & & & & \\
\hline Randomization & & $x$ & & & & & & \\
\hline \multicolumn{9}{|l|}{ Intervention } \\
\hline Type of procedure & & & $x$ & & & & & \\
\hline CPB (in minutes) & & & $x$ & & & & & \\
\hline Number of red blood cell transfusions & & & $x$ & & & & & \\
\hline Number of and reasons for manual insufflation & & & $x$ & & & & & \\
\hline \multicolumn{9}{|l|}{ Assessments } \\
\hline Temperature & & & & $x$ & $x$ & $x$ & & \\
\hline $\mathrm{PaO} 2$ & & & & $x$ & $x$ & $x$ & & \\
\hline $\mathrm{FiO} 2$ & & & & $x$ & $x$ & $x$ & & \\
\hline Ventilation mode & & & & $x$ & $x$ & $x$ & & \\
\hline Hemoglobinemia & & & & $x$ & $x$ & $x$ & & \\
\hline Leucocytemia & & & & $x$ & $x$ & $x$ & & \\
\hline Quantity of bleeding & & & & $x$ & $x$ & $x$ & & \\
\hline Collection of data on the occurrence of primary ${ }^{d}$ and secondary ${ }^{e}$ endpoints & & & & $x$ & $x$ & $x$ & $x$ & $x$ \\
\hline Serious adverse events & & & & $x$ & $x$ & $x$ & $x$ & $x$ \\
\hline
\end{tabular}

Abbreviations: CPB cardiopulmonary bypass; D day; FiO2 fraction of inspired oxygen; PaO2 arterial oxygen tension; FEV (1) forced expiratory volume 1; FVC forced vital capacity

aTime points: enrollment, interventions and assessments

bysical examination: weight, height

'History of previous disease: diabetes mellitus, peripheral arterial disease, pulmonary comorbidity, pulmonary infection in the past 30 days

dPrimary endpoints: overall death, early respiratory failure defined as $\mathrm{PaO} 2 / \mathrm{FiO} 2$ ratio $<200$ at 1 hour after arrival in the ICU, heavy oxygenation support (defined as a patient requiring either non-invasive ventilation, mechanical ventilation or high-flow oxygen) at 2 days after arrival in the ICU or ventilator-acquired pneumonia as defined by the Center of Disease Control

eSecondary endpoints: pneumothorax, CPB duration, volume of postoperative bleeding, red blood cell transfusions, requirements for revision surgery, length of stay in the ICU and in the hospital and total hospitalization costs 
of Personal Information and the National Health Law. The Regional Ethics Committee has approved the study protocol, which was also approved by the French Data Protection Agency. The trial protocol is registered at ClinicalTrials.gov (NCT03098524). Patients are enrolled only after written informed consent has been obtained.

\section{Discussion}

Postoperative pulmonary complications (PPCs) are common and serious complications after cardiac surgery [15], despite continuing improvements in CPB techniques and postoperative intensive care. They are broadly defined as conditions affecting the respiratory tract that can significantly impact on patient outcomes and health economics $[16,17]$.

During CBP, the lungs are under perfused, non-ventilated or supplied with low continuous ventilation, depending on the center protocol [18]. Clinical trials have suggested that preventive lung-protective ventilation may improve outcomes in patients undergoing high-surgery [16].

The goal of the MECANO trial is to compare the effects of no ventilation during CBP and LTV ventilation of 3 $\mathrm{mL} / \mathrm{kg}$ with a PEEP of $5 \mathrm{cmH} 2 \mathrm{O}$ during $\mathrm{CPB}$ in cardiac surgery. We believe that the present study has several strengths. First, the number of patients to be included (n $=1500$ ) is ambitious. Several previous studies aimed to prove the beneficial effect of protective ventilation in cardiac surgery [16]. However, most trials were insufficiently powered or biased, leading to high heterogeneity and lack of conclusive results [13, 19-31]. The CPBVENT trial (NCT02090205) aims to answer a similar question. Although multicenter by design, it is a single-blind study and focuses on indirect outcomes ( $\mathrm{PaO} 2 / \mathrm{FiO} 2$ ratio only) instead of harder clinical endpoints such as hospitalacquired pneumonia or death. This explains why the number of patients to be included in CPBVENT is smaller ( $\mathrm{n}=720$ vs. $\mathrm{n}=1500$ in our study). Moreover, CPBVENT compares three ventilation strategies (no ventilation, continuous positive airway pressure (CPAP) and LTV ventilation), which may decrease the power of the study [13]. Finally, the inclusion criteria are stricter, decreasing the possibility to generalize the results.

Second, the MECANO trial addresses observer bias by using a double-blind design, with investigators only involved in the post-surgery setting. As such, they are never aware of the allocation arm of the included patients. Randomization ensures equity and balance between the two treatment strategies. In-hospital follow up allows for complete follow up of all patients and is sufficiently pertinent, as postoperative pulmonary complications are expected to happen within the hospital stay after surgery. Third, data on all variables that may account for the increased risk of postoperative pulmonary complications are collected at baseline, ensuring equivalence between the two treatment strategies.
Limitations of the MECANO trial include its single-center design, although the number of physicians accounts for a wide scope of practices, all in line with current guidelines. Second, the surgeon has the final say in the type of mechanical ventilation, i.e. he can stop any type of ventilation strategy during $\mathrm{CPB}$ as he sees fit. This bias is addressed by systematically collecting the reason for and number of times that this may happen. Analyses will be performed on an intention-to-treat and per-protocol basis. Moreover, this will generally show how feasible or not, a maintained LTV ventilation might be and guide clinical practice accordingly.

In conclusion, the MECANO trial should help determine whether low-tidal ventilation is superior to no-ventilation, during cardiac surgery with $\mathrm{CPB}$. It is the first doubleblind trial of this kind, with a large population and focusing on hard clinical endpoints (Table 2, Additional file 1).

\section{Trial status}

The first patients were randomized on 1 May 2017. The inclusion of participants is ongoing and is expected to continue until 15 April 2019.

\section{Additional file}

Additional file 1: SPIRIT 2013 Checklist: Recommended items to address in a clinical trial protocol and related documents. (DOCX $47 \mathrm{~kb}$ )

\section{Abbreviations}

CPAP: Continuous positive airway pressure; CPB: Cardiopulmonary bypass; CRF: Case report form; FiO2: Fraction of inspired oxygen; ICU: Intensive care unit; LRM: Lung recruitment maneuvers; LTV: Low-tidal volume; noV: No ventilation; PaO2: Partial pressure of oxygen; PEEP: Positive end-expiratory pressure; PPCs: Post-operative pulmonary complications; VAP: Ventilationacquired pneumonia

\section{Acknowledgements}

The authors thank Dr J-F Dreyfus for his statistical expertise and Mr S. Novak for his contribution and energy in the development and deployment of the study protocol.

\section{Funding}

Self-sponsored.

\section{Availability of data and materials}

Not applicable.

\section{Authors' contributions}

LSN participated in the conception and design of the study, wrote the study protocol and designed the statistical analysis. MM participated in the writing of the manuscript, drawing of figures, the collection of consent forms and critical revision of the article. PE participated in the funding project, design of the study, inclusion of patients and critical revision of the article. AB participated in the funding project, design of the study, inclusion of patients and critical revision of the article. J-DLK participated in the study design, critical revision of the study protocol and application of the protocol. SA participated in the revision of the study protocol, its application and critical revision of the article. TW participated in the revision of the study protocol, its application and critical revision of the article. J-MG participated in the revision of the study protocol, its application and critical revision of the article. HG participated in the study design, critical revision of the study protocol and application of the protocol. PS participated in the funding project, design of the study, inclusion of patients and critical revision of the article. All authors read and approved the final manuscript. 


\section{Authors' information}

All authors belong to CMC Ambroise Paré located in Neuilly-sur-Seine, France.

\section{Ethics approval and consent to participate}

Institutional Review Board (Comité de Protection des Personnes) approval: 22 November 2016 (Hopital de Bicêtre, 78 rue du général Leclerc, 94275 Le Kremlin Bicetre). Declared on ClinicalTrials.gov under NCT03098524. Every patient was clearly informed and was required to sign to consent before inclusion in the study.

\section{Consent for publication}

Approved by the co-authors.

\section{Competing interests}

The authors declare that they have no competing interests.

\section{Publisher's Note}

Springer Nature remains neutral with regard to jurisdictional claims in published maps and institutional affiliations.

\section{Author details}

'Critical Care Medicine Department, CMC Ambroise Paré, 25-27 Boulevard Victor Hugo, 92200 Neuilly-sur-Seine, France. ${ }^{2}$ Cardiac Surgery Department, CMC Ambroise Paré, Neuilly-sur-Seine, France. ${ }^{3}$ Anesthesiology Department CMC Ambroise Paré, Neuilly-sur-Seine, France.

\section{Received: 29 July 2017 Accepted: 8 November 2017}

\section{Published online: 02 December 2017}

\section{References}

1. Canet J, Gallart L, Gomar C, et al. Prediction of postoperative pulmonary complications in a population-based surgical cohort. Anesthesiology. 2010; 113:1338-50.

2. Kollef MH. Ventilator-associated pneumonia. A multivariate analysis. JAMA 1993:270:1965-70

3. Kollef MH, Sharpless L, Vlasnik J, et al. The impact of nosocomial infections on patient outcomes following cardiac surgery. Chest. 1997;112:666-75.

4. Allou N, Bronchard R, Guglielminotti J, et al. Risk factors for postoperative pneumonia after cardiac surgery and development of a preoperative risk score*. Crit Care Med. 2014:42:1150-6.

5. Bouza E, Perez A, Munoz P, et al. Ventilator-associated pneumonia after heart surgery: a prospective analysis and the value of surveillance. Crit Care Med. 2003:31:1964-70

6. Ibanez J, Riera M, Amezaga R, et al. Long-term mortality after pneumonia in cardiac surgery patients: a propensity-matched analysis. J Intensive Care Med. 2016;31:34-40

7. Passaroni AC, Silva MA, Yoshida WB. Cardiopulmonary bypass: development of John Gibbon's heart-lung machine. Rev Bras Cir Cardiovasc. 2015;30:235-45.

8. Loeckinger $\mathrm{A}$, Kleinsasser $\mathrm{A}$, Lindner $\mathrm{KH}$, et al. Continuous positive airway pressure at $10 \mathrm{~cm} \mathrm{H(2)O} \mathrm{during} \mathrm{cardiopulmonary} \mathrm{bypass} \mathrm{improves}$ postoperative gas exchange. Anesth Analg. 2000;91:522-7.

9. Bignami E, Guarnieri M, Saglietti F, et al. Mechanical ventilation during cardiopulmonary bypass: a review. J Cardiothorac Vasc Anesth. 2016;30(6):1668-75.

10. $\mathrm{Ng} \mathrm{CS}$, Arifi AA, Wan $\mathrm{S}$, et al. Ventilation during cardiopulmonary bypass: impact on cytokine response and cardiopulmonary function. Ann Thorac Surg. 2008:85:154-62.

11. Zupancich E, Paparella D, Turani F, et al. Mechanical ventilation affects inflammatory mediators in patients undergoing cardiopulmonary bypass for cardiac surgery: a randomized clinical trial. J Thorac Cardiovasc Surg. 2005; 130:378-83.

12. Coppola S, Froio S, Chiumello D. Protective lung ventilation during general anesthesia: is there any evidence? Crit Care. 2014:18:210.

13. Bignami E, Guarnieri M, Saglietti F, et al. Different strategies for mechanical VENTilation during CardioPulmonary Bypass (CPBVENT 2014): study protocol for a randomized controlled trial. Trials. 2017:18:264.

14. Centers for Disease Control and Prevention. Pneumonia (Ventilator associated [VAP] and non-ventilator-associated Pneumonia [PNEU]). 2017:6 1-17. https://www.cdc.gov/nhsn/pdfs/pscmanual/pcsmanual_current.pdf.

15. Futier E, Constantin JM, Paugam-Burtz C, et al. A trial of intraoperative lowtidal-volume ventilation in abdominal surgery. N Engl J Med. 2013;369:428-37.
16. Chi D, Chen C, Shi Y, et al. Ventilation during cardiopulmonary bypass for prevention of respiratory insufficiency: a meta-analysis of randomized controlled trials. Medicine. 2017;96:e 6454.

17. Kelkar KV. Post-operative pulmonary complications after non-cardiothoracic surgery. Indian J Anaesth. 2015;59:599-605.

18. Romagnoli S, Ricci Z. Lung protective ventilation in Cardiac Surgery. Heart Lung Vessel. 2015;7:5-6.

19. Zabeeda D, Gefen R, Medalion B, et al. The effect of high-frequency ventilation of the lungs on postbypass oxygenation: a comparison with other ventilation methods applied during cardiopulmonary bypass. J Cardiothorac Vasc Anesth. 2003:17:40-4

20. Claxton BA, Morgan P, McKeague H, et al. Alveolar recruitment strategy improves arterial oxygenation after cardiopulmonary bypass. Anaesthesia. 2003;58:111-6.

21. Ayad AE, Hamed HF. Continuous positive airway pressure (CPAP) during cardiopulmonary bypass attenuates postoperative pulmonary dysfunction and complications. Egypt J Anaesth. 2003;19:345-51.

22. Figueiredo L, Araujo S, Abdala RC, et al. CPAP at $10 \mathrm{~cm} \mathrm{H} 2 \mathrm{O}$ during cardiopulmonary bypass does not improve postoperative gas exchange. Rev Bras Cir Cardiovasc. 2008;23(2):209-15.

23. Bockeria LA, Zaharchenko A, Antonenko D, et al. A study assessing the potential benefit of continued ventilation during cardiopulmonary bypass. Interact Cardiovasc Thorac Surg. 2008:7:14-7.

24. Scherer M, Detmer DS, Meininger D, et al. Alveolar recruitment strategy during cardiopulmonary bypass does not improve postoperative gas exchange and lung function. Cardiovasc Eng. 2009;9:1-5.

25. Davoudi M, Farhanchi A, Moradi A, et al. The effect of low tidal volume ventilation during cardiopulmonary bypass on postoperative pulmonary function. J Tehran Heart Cent. 2010;5:128-31.

26. Beer L, Szerafin T, Mitterbauer A, et al. Continued mechanical ventilation during coronary artery bypass graft operation attenuates the systemic immune response. Eur J Cardiothorac Surg. 2013;44:282-7.

27. Beer L, Szerafin T, Mitterbauer A, et al. Low tidal volume ventilation during cardiopulmonary bypass reduces postoperative chemokine serum concentrations. Thorac Cardiovasc Surg. 2014;62:677-82.

28. Beer L, Warszawska JM, Schenk P, Debreceni T, et al. Intraoperative ventilation strategy during cardiopulmonary bypass attenuates the release of matrix metalloproteinases and improves oxygenation. J Surg Res. 2015; 195:294-302.

29. Durukan A, Salman N, Unal EU, et al. Ventilation during cardiopulmonary bypass did not attenuate inflammatory response or affect postoperative outcomes. Cardiovasc J Afr. 2013;24:224-30

30. Gagnon J, Laporta D, Beique F, et al. Clinical relevance of ventilation during cardiopulmonary bypass in the prevention of postoperative lung dysfunction. Perfusion. 2010;25:205-10.

31. Macedo Fl, Costa AC, Pham SM, et al. Beating heart surgery with pulmonary perfusion and ventilation during cardiopulmonary bypass: target organs' perfusion without plegia. Semin Thorac Cardiovasc Surg. 2012;24:308-10.

\section{Submit your next manuscript to BioMed Central and we will help you at every step:}

- We accept pre-submission inquiries

- Our selector tool helps you to find the most relevant journal

- We provide round the clock customer support

- Convenient online submission

- Thorough peer review

- Inclusion in PubMed and all major indexing services

- Maximum visibility for your research

Submit your manuscript at www.biomedcentral.com/submit
) Biomed Central 